\title{
Inhibitive Action of Ferrous Gluconate on Aluminum Alloy in Saline Environment
}

\author{
Patricia Abimbola Idowu Popoola, ${ }^{1}$ Sanni Omotayo, ${ }^{1}$ \\ Cleophas A. Loto, ${ }^{1,2}$ and Olawale Muhammed Popoola ${ }^{3}$ \\ ${ }^{1}$ Department of Chemical, Metallurgical and Materials Engineering, Tshwane University of Technology, PMB. X680, \\ Pretoria 0001, South Africa \\ ${ }^{2}$ College of Science and Technology, Covenant University, Ota, Ogun State, Nigeria \\ ${ }^{3}$ Department of Electrical Engineering, Tshwane University of Technology, PMB. X680, Pretoria 0001, South Africa
}

Correspondence should be addressed to Patricia Abimbola Idowu Popoola; popoolaapi@tut.ac.za

Received 26 June 2013; Revised 14 October 2013; Accepted 1 November 2013

Academic Editor: Martin Crimp

Copyright (C) 2013 Patricia Abimbola Idowu Popoola et al. This is an open access article distributed under the Creative Commons Attribution License, which permits unrestricted use, distribution, and reproduction in any medium, provided the original work is properly cited.

\begin{abstract}
The corrosion of aluminum in saline environment in the presence of ferrous gluconate was studied using weight loss and linear polarization methods. The corrosion rates were studied in different concentrations of ferrous gluconate $0.5,1.0,1.5$, and $2.0 \mathrm{~g} / \mathrm{mL}$ at $28^{\circ} \mathrm{C}$. Experimental results revealed that ferrous gluconate in saline environment reduced the corrosion rate of aluminum alloy at the different concentrations studied. The minimum inhibition efficiency was obtained at $1.5 \mathrm{~g} / \mathrm{mL}$ concentration of inhibitor while the optimum inhibition efficiency was achieved with $1.0 \mathrm{~g} / \mathrm{mL}$ inhibitor concentration. The results showed that adsorption of ferrous gluconate on the aluminium alloy surface fits Langmuir adsorption isotherm. The potentiodynamic polarization results showed that ferrous gluconate is a mixed type inhibitor. Ferrous gluconate acted as an effective inhibitor for aluminium alloy within the temperature and concentration range studied. The data obtained from weight loss and potentiodynamic polarization methods were in good agreement.
\end{abstract}

\section{Introduction}

Aluminum and its alloys are known to be used in industries due to their weight-to-strength ratios, good resistance to corrosion, excellent workability, and high electrical conductivity [1-4]. In spite of these attractive properties of aluminum, in the presence of aggressive ions, like chloride, the protective layer can be locally destroyed and corrosive attack takes place $[5,6]$. Corrosion control and prevention are unavoidable major scientific issues that must be addressed daily as far as there are increasing applications of metallic materials in all facets of technological development [7]. The main corrosion issue with aluminum and its alloys is the localized breakdown of the passive film, which leads to the initiation and growth of corrosion pits in chloride medium [8-10]. Corrosion can be prevented by appropriate modifications of the environment which in turn suppress, retard, or completely stop the cathodic or anodic reactions or both. This can be achieved by the use of inhibitors [1113]. Corrosion inhibitors are substances which when added in small concentrations to corrosive environments decrease or prevent the reaction of the metal with the media. Inhibitors are added to many systems such as refinery units, cooling systems, pipelines, oil and gas production units [14]. Due to the various economic importance and industrial applications of aluminum and its alloys, its protection against corrosion has attracted much attention [15-22]. The authors [23] studied the corrosion inhibition of aluminum alloy in $2 \mathrm{M} \mathrm{HCl}$ and $\mathrm{HNO}_{3}$ with Arachis hypogaea natural oil as an inhibitor using potentiodynamic polarization and gravimetric techniques at $25^{\circ} \mathrm{C}$. The obtained results showed that Arachis hypogaea oil in $2 \mathrm{M} \mathrm{HCl}$ and $\mathrm{HNO}_{3}{ }^{-}$solutions decreased the corrosion rate of aluminum alloy at different concentrations of inhibitor considered; the scanning electron microscope 
TABLE 1: Chemical composition of aluminium alloy (\%wt).

\begin{tabular}{lcccccccccc}
\hline $\mathrm{Si}$ & $\mathrm{Fe}$ & $\mathrm{Cu}$ & $\mathrm{Mn}$ & $\mathrm{Mg}$ & $\mathrm{Cr}$ & $\mathrm{Ti}$ & $\mathrm{Ca}$ & $\mathrm{Zr}$ & $\mathrm{V}$ & $\mathrm{Al}$ \\
\hline 0.157 & 0.282 & 0.0025 & 0.024 & 0.51 & 0.023 & 0.006 & 0.0011 & 0.002 & 0.0035 & Balance \\
\hline
\end{tabular}

surface morphology of as-corroded uninhibited condition showed severe pits and damage formation than those of ascorroded inhibited conditions. The authors concluded that additions of Arachis hypogaea as corrosion inhibitor for aluminum alloy indicate a high inhibition efficiency, potential value, and polarization resistance with decrease in current density. The authors of [24] studied the interfacial behavior of fluconazole (FLC) as a corrosion inhibitor for aluminum in hydrochloric acid solution between hydrochloric acid and aluminum using weight loss method. The experimental results revealed that fluconazole exhibits an excellent corrosion inhibitor property for aluminum in hydrochloric acidic medium. The authors of [25] worked on the effect of solution $\mathrm{pH}$ on the anticorrosion performance of different inhibitors $\mathrm{K}_{2} \mathrm{Cr}_{2} \mathrm{O}_{7}, \mathrm{CeCl}_{3}$, and $\mathrm{Ce}(\mathrm{dbp})_{3}$ on aluminum alloy (AA2024-T3) using the multielectrode and conventional potentiodynamic polarization methods. The results showed that the $\mathrm{K}_{2} \mathrm{Cr}_{2} \mathrm{O}_{7}$ at $10^{-4} \mathrm{M}$ after 30 min of exposure time behaves as the best inhibitor across the studied $\mathrm{pH}$ range. The authors of [26] worked on the influence of bromide and iodide ions on the inhibitive effect of polyacrylamide (PA) on aluminum corrosion in $\mathrm{HCl}$ solution using weight loss, hydrogen evolution, and thermometric techniques at 30 and $60^{\circ} \mathrm{C}$. The experimental results show that the halide additives synergistically increased the inhibition efficiency of polyacrylamide and the increase in inhibition efficiency was found to be more obvious in iodide than bromide ions.

Gluconic acid occurs naturally in honey, fruit, kombucha tea, and wine [27]. They are environmentally suitable nontoxic compounds, and gluconates are part of the successful commercial corrosion inhibitors. Gluconic acid and its derivatives are used as ingredients in various hygienic products, for scale removal in metal cleanings, as household cleaning compounds including mouth washer, metal finishing, and for water treatment operation. Sodium, calcium, and zinc salts of gluconic acid have been reported to be effective nontoxic inhibitors for tin, iron, and mild steel in near neutral solution [27-29]. The efficiency of gluconate inhibition depends on $\mathrm{pH}$ value, inhibitor concentration, chemical composition of investigated solution, the nature of cations introduced in the solution as gluconate and the state of the metal surface [30]. Different mechanisms of corrosion inhibition by gluconate were proposed. It is speculated that gluconate can repair the oxide film by its adsorption on the exposed metal surface in weak spots of porous oxide film. Gluconates can be incorporated in the oxide film during its formation and/or gluconate are forming more or less soluble complexes that can be precipitated on the metal surface [30]. In view of this, it is essential to study the corrosion behavior of aluminum in ferrous gluconate solution. The present study aimed at evaluating the potential of ferrous gluconate as an inhibitor for aluminum alloy in saline medium using weight loss and potentiodynamic polarization methods.

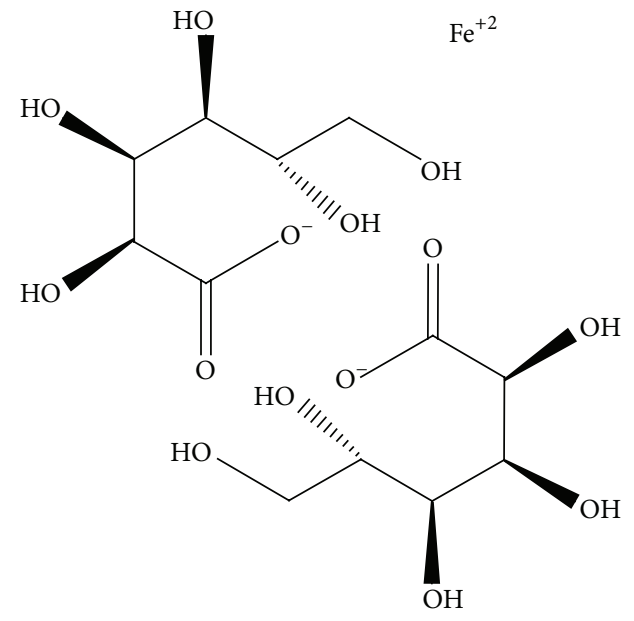

FIGURE 1: Molecular structure of ferrous gluconate.

\section{Experimental}

2.1. Materials and Sample Preparation. Aluminum alloy with the chemical composition presented in Table 1 was used as substrate material for weight loss and potentiodynamic polarization studies. The aluminum alloy plate was cut using a Struers cutting machine with a Discotom-5 cut-off wheel. A Struers lubricant which works as a coolant was used during cutting. The substrate was cut and machined to dimensions $12 \times 12 \times 12 \mathrm{~mm}$. The aggressive solution of sodium chloride purchased from SMM Instruments (Pty) Ltd, South Africa, was used for this study. The chemical structure of ferrous gluconate is shown in Figure 1 purchased from SMM Instruments (Pty) Ltd, South Africa. An insulated copper wire was connected to one side of the sample using an aluminum conducting tape and cold mounted in methyl methacrylate resin leaving one surface of an area of $1 \mathrm{~cm}^{2}$ for potentiodynamic polarization measurement; the exposed surface area was abraded with different grates of emery papers, degreased with acetone, rinsed in distilled water, dried, weighed, and stored in a desiccator. The initial weight of the samples was taken and recorded. In each experiment, $0.05 \mathrm{M} \mathrm{NaCl}$ solution was prepared freshly as required. Corrosion studies were carried out at $28^{\circ} \mathrm{C}$.

2.2. Weight Loss Measurement. The weight loss test was conducted on the aluminum alloy weighed samples in the absence and presence of different concentrations of inhibitor at $28^{\circ} \mathrm{C}$. Volume of the solution used was $200 \mathrm{~mL}$ and the concentration of the inhibitor was in the range of $0.5,1.0$, 1.5 , and $2.0 \mathrm{~g} / \mathrm{mL}$ in saline environment. The samples were washed with distilled water, dried in acetone, and weighed at an interval of 48 hours of immersion time. Corrosion 
TABLE 2: Electrochemical polarization parameters for aluminium alloy in $0.05 \mathrm{M} \mathrm{NaCl}$ solution in the absence and presence of ferrous gluconate at $28^{\circ} \mathrm{C}$.

\begin{tabular}{lcccccc}
\hline $\begin{array}{l}\text { Concentration of } \\
\text { inhibitor } \\
(\mathrm{g} / \mathrm{mL})\end{array}$ & $\begin{array}{c}\text { Current density } \\
\left(\mathrm{A} / \mathrm{cm}^{2}\right)\end{array}$ & $\begin{array}{c}\text { Anodic Tafel } \\
\text { constant } \\
(\mathrm{V} / \mathrm{dec})\end{array}$ & $\begin{array}{c}\text { Cathodic Tafel } \\
\text { constant } \\
(\mathrm{V} / \mathrm{dec})\end{array}$ & $\begin{array}{c}\text { Linear } \\
\text { polarization } \\
\left(\Omega \mathrm{cm}^{2}\right)\end{array}$ & $\begin{array}{c}\text { Corrosion } \\
\text { potential } \\
(\mathrm{V})\end{array}$ & $\begin{array}{c}\text { Corrosion rate } \\
(\mathrm{mm} / \mathrm{yr})\end{array}$ \\
\hline 0.0 & $8.59 E-06$ & 0.05087 & 0.08004 & $1.57 E+03$ & -0.75893 & 0.27787 \\
0.5 & $7.21 E-07$ & 0.17081 & 0.39458 & $7.18 E+04$ & -1.05640 & 0.02334 \\
1.0 & $4.96 E-09$ & 0.74904 & 1.50350 & $4.38 E+07$ & -0.34318 & 0.00016 \\
1.5 & $4.76 E-07$ & 0.52492 & 0.54034 & $2.43 E+05$ & -0.57367 & 0.00554 \\
2.0 & $6.49 E-09$ & 1.92670 & 0.96634 & $4.30 E+07$ & -0.34318 & 0.00021 \\
\hline
\end{tabular}

rate, degree of surface coverage, and inhibitor efficiency were determined for each inhibitor concentration using the following equations:

$$
\text { Corrosion rate }\left(\frac{\mathrm{mm}}{\mathrm{yr}}\right)=\frac{87.6 \mathrm{~W}}{D A T},
$$

where $W$ is weight loss ( $\mathrm{mg}), D$ is specimen density $\left(\mathrm{g} / \mathrm{cm}^{3}\right)$, $A$ is specimen area $\left(\mathrm{cm}^{2}\right)$, and $T$ is exposure time (hour)

$$
\text { Degree of surface coverage }(\theta)=\mathrm{CR}^{\circ}-\frac{\mathrm{CR}}{\mathrm{CR}^{\circ}}
$$

Percentage inhibition efficiency (IE)

$$
=\left(\mathrm{CR}^{\circ}-\frac{\mathrm{CR}}{\mathrm{CR}^{\circ}}\right) \times 100,
$$

where $\mathrm{CR}$ and $\mathrm{CR}^{\circ}$ are the corrosion rates of the specimens in the presence and absence of inhibitor, respectively.

\subsection{Potentiodynamic Polarization Measurements. Potentio-} dynamic polarization tests were carried out using three electrode glass cells with an AUTOLAB Potentiostat (model Reference-668) which was connected to a personal computer to control the experiments. A graphite rod, saturated $\mathrm{Ag} / \mathrm{AgCl}$, and aluminum alloy specimen were used as counter, reference, and working electrode respectively. The polarization experiments data were analyzed by NOVA software version 1.8 . The polarization curves were carried out with $-1.5 \mathrm{~V}$ cathodic potential and $+1.5 \mathrm{~V}$ anodic potential at a scan rate of $0.0016 \mathrm{~V} / \mathrm{sec}$. From the linear Tafel plot of the cathodic and anodic curves, corrosion rate, corrosion potential $\left(E_{\text {corr }}\right)$, and corrosion current densities $\left(i_{\text {corr }}\right)$ were obtained.

2.4. Scanning Electron Microscopy (SEM) Analysis. The scanning electron microscope images of the aluminum alloy samples were recorded via JEOL JSM-7600F scanning electron microscope.

\section{Results and Discussion}

The variations in corrosion rate and percentage inhibition efficiency (\%IE) with immersion time at different concentrations of ferrous gluconate for 28 days of exposure are

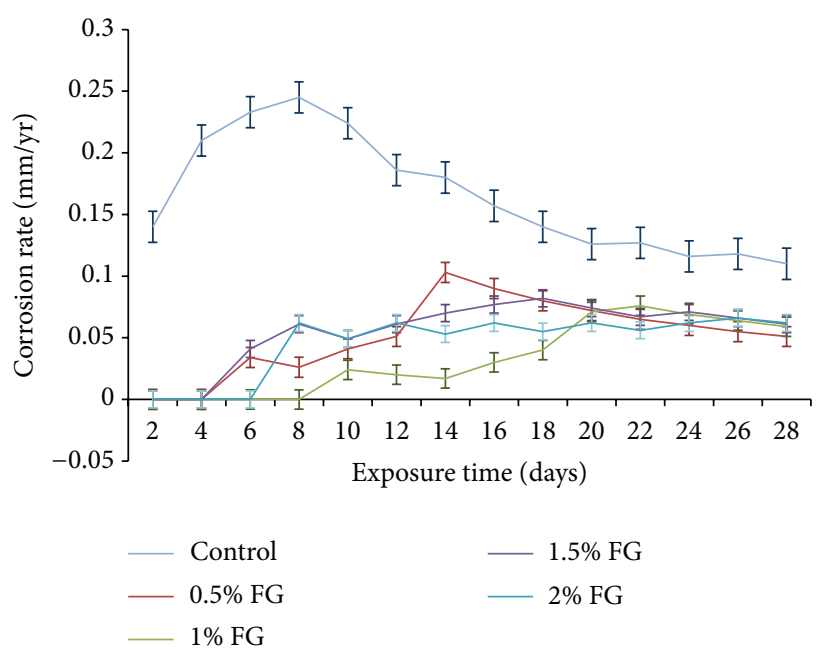

FIGURE 2: Variation of corrosion rate with exposure time for aluminum alloy specimen immersed in $0.05 \mathrm{M} \mathrm{NaCl}$ solution with ferrous gluconate addition.

shown in Figures 2 and 3. Table 2 shows the numerical values of the corrosion current density $\left(i_{\text {corr }}\right)$, corrosion potential $\left(E_{\text {corr }}\right)$, linear polarization resistance (LPR), corrosion rate, and anodic and cathodic Tafel slopes $\left(\beta_{a}\right.$ and $\left.\beta_{c}\right)$ with different concentrations of ferrous gluconate. Figure 4 shows the potentiodynamic polarization curves for aluminum alloy dissolution in saline solution in the absence and presence of different concentrations of ferrous gluconate at $28^{\circ} \mathrm{C}$. Figure 5 shows the SEM micrograph while Figure 6 illustrates the Langmuir adsorption isotherm. In Figure 7, a comparative chart of the inhibition efficiency obtained from weight loss and potentiodynamic polarization methods was presented.

3.1. Corrosion Rate and Inhibitor Efficiency. From the results, the corrosion rate of the aluminum alloy in saline environment decreased in the presence of all the different concentrations of inhibitor studied. Figure 2 shows that aluminum alloy in $0.05 \mathrm{M} \mathrm{NaCl}$ solution with $1.0 \mathrm{~g} / \mathrm{mL}$ concentration of inhibitor showed an excellent corrosion resistance. In the presence of $0.5 \mathrm{~g} / \mathrm{mL}$ concentration of ferrous gluconate, the corrosion rate value was $0.051 \mathrm{~mm} / \mathrm{yr}$ after 28 days of exposure time compared to the absence of ferrous gluconate which gave $0.110 \mathrm{~mm} / \mathrm{yr}$ after 28 days of exposure 


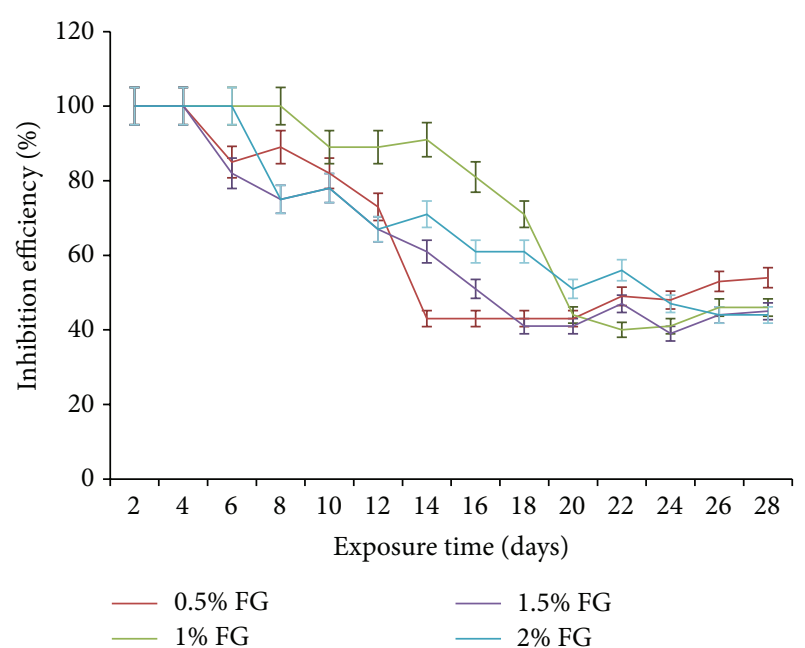

FIGURE 3: Variation of inhibition efficiency with exposure time for aluminum alloy specimen immersed in $0.05 \mathrm{M} \mathrm{NaCl}$ solution with ferrous gluconate addition.

time. This shows $54 \%$ reduction in corrosion rate value compared to the absence of inhibitor. This revealed that ferrous gluconate inhibits the corrosion of aluminum alloy in saline medium. The results showed that percentage inhibition efficiency (\%IE) of ferrous gluconate depends on the inhibitor concentrations. The results also indicated that the optimum inhibitor efficiency of ferrous gluconate was obtained at a concentration of $1.0 \mathrm{~g} / \mathrm{mL}$ with 100 percentage efficiency. It is generally assumed that the adsorption of inhibitor at metal/solution interface is the first step in the mechanism of inhibition in aggressive media [29]. It was observed that at inhibitor concentration greater than $1.0 \mathrm{~g} / \mathrm{mL}$, the corrosion rate was slightly increased. This could be attributed to excess addition of inhibitor to the saline medium and that certain concentration of ferrous gluconate will have a detrimental effect on corrosion rate.

Therefore, the adsorption of ferrous gluconate onto the surface of the aluminum alloy at all concentration studied prevents the breakdown of the film leading to higher corrosion resistance of the aluminum alloy. The inhibition effect of ferrous gluconate decreases gradually with increasing concentration values, which implies that ferrous gluconate has a beneficial effect even at low concentrations. This suggests the formation of soluble ferrous gluconate complex $[29,31,32]$.

3.2. Potentiodynamic Polarization Measurements. Results obtained show that the cathodic and anodic curves demonstrated a Tafel type behaviour. The presence of ferrous gluconate significantly changes both anodic and cathodic region when compared to the absence of inhibitor [33]. Thus, cathodic and anodic reactions were interfered in the presence of ferrous gluconate, which implies that the ferrous gluconate showed an effective inhibitory effect on cathodic hydrogen reduction reaction and anodic dissolution of aluminum alloy. Also, the result implies that ferrous gluconate acts as a mixed

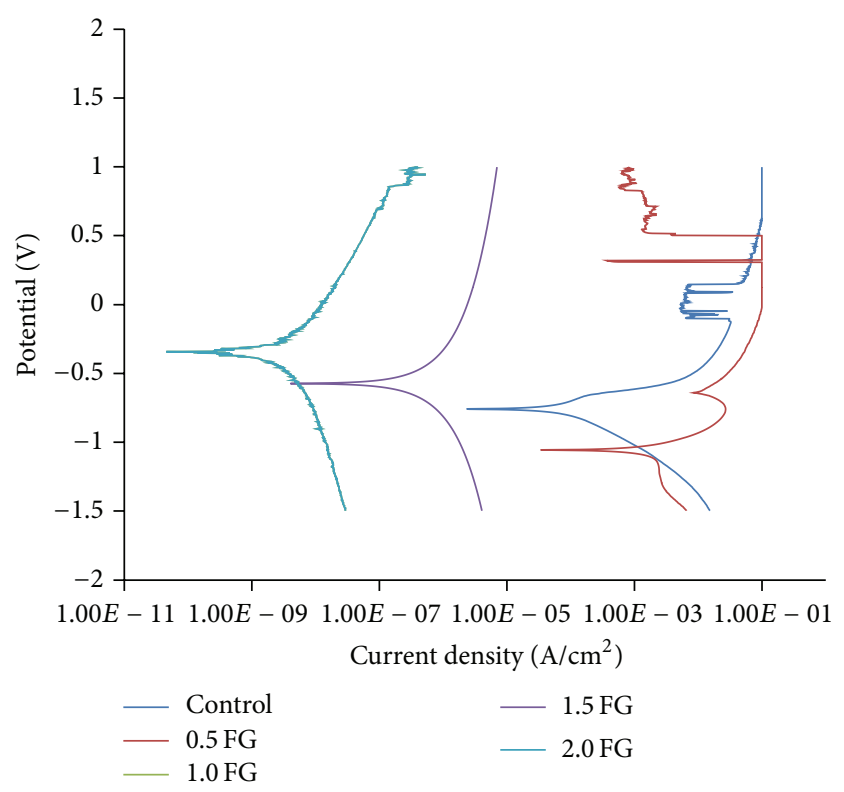

FIGURE 4: Linear polarization of aluminum alloy in $0.05 \mathrm{M} \mathrm{NaCl}$ solution/ferrous gluconate environment at $28^{\circ} \mathrm{C}$.

type inhibitor. This can be explained on the basis of specific adsorption of ferrous gluconate anions and on the basis of the competitive adsorption between the ferrous gluconate anions and $\mathrm{Cl}^{-}$ions on the electrode surface and therefore retard the $\mathrm{Cl}^{-}$destructive action [34]. Apparently, the bond between the surface atoms of the metal and the adsorbed inhibitor anions is strong which can inhibit oxidation [34]. The corrosion potential $\left(E_{\text {corr }}\right)$ values shifted to the less negative values in the presence of inhibitor. From Table 2, it is clear that the corrosion current value decreased from $8.59 \mathrm{E}-06 \mathrm{~A} / \mathrm{cm}^{2}$ to $4.96 \mathrm{E}-09 \mathrm{~A} / \mathrm{cm}^{2}$ in the presence of $1.0 \mathrm{~g} / \mathrm{mL}$ concentration of ferrous gluconate in $0.05 \mathrm{M} \mathrm{NaCl}$ solution; $b_{a}$ and $b_{c}$ values changed significantly and $E_{\text {corr }}$ shifted to cathodic region; hence, ferrous gluconate acted as mixed type inhibitor.

The polarization resistance value of aluminum increases from $1.6 \mathrm{E} 03 \mathrm{~cm}^{2}$ in the absence of inhibitor to $4.38 \mathrm{E} 07 \mathrm{~cm}^{2}$ in the presence of $1.0 \mathrm{~g} / \mathrm{mL}$ concentration of inhibitor, and the corrosion rate value decreases from 0.27787 to $0.000162 \mathrm{~mm} / \mathrm{yr}$ in the presence of $1.0 \mathrm{~g} / \mathrm{mL}$ (ses Figure 8). The decrease in corrosion rate and corrosion current density $\left(i_{\text {corr }}\right)$ in the presence of all the different concentrations of ferrous gluconate studied proved that ferrous gluconate act as an effective corrosion inhibitor for aluminum alloy in saline environment at $28^{\circ} \mathrm{C}$.

Anodic and cathodic processes of aluminum corrosion in saline medium are dissolution of aluminum and reduction of dissolved oxygen, respectively, as [35]

$$
\begin{gathered}
4 \mathrm{Al} \longrightarrow 4 \mathrm{Al}^{3+}+12 \mathrm{e}^{-} \\
3 \mathrm{O}_{2}+6 \mathrm{H}_{2} \mathrm{O}+12 \mathrm{e}^{-} \longrightarrow 12 \mathrm{OH}^{-} .
\end{gathered}
$$




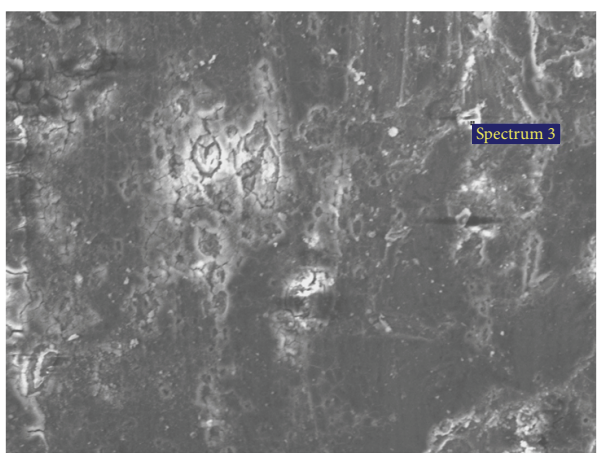

$100 \mu \mathrm{m}$
Electron image 1

(a)

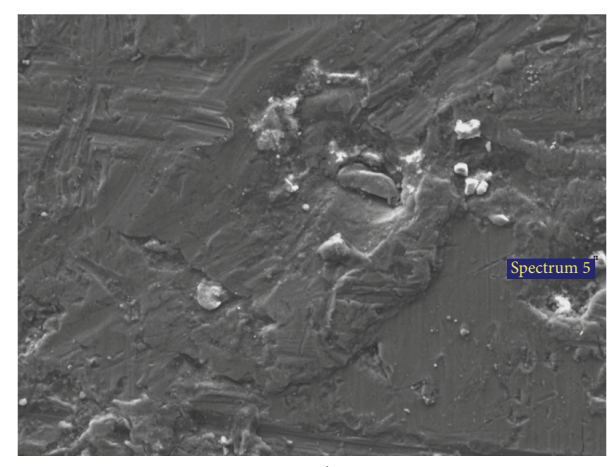

$100 \mu \mathrm{m}$
Electron image 1

(b)

FIGURE 5: SEM micrograph of the aluminum alloy sample (a) in $0.05 \mathrm{M} \mathrm{NaCl}$ solution (b) with ferrous gluconate after 28 days of immersion.

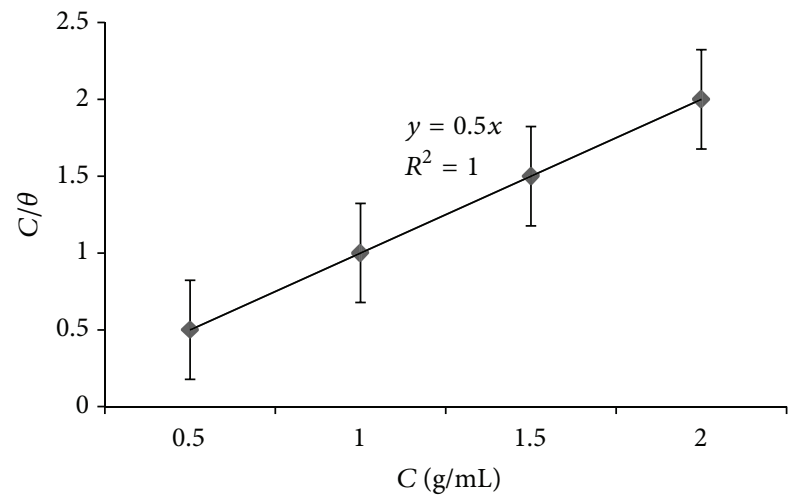

FIGURE 6: Langmuir adsorption isotherm of ferrous gluconate on the aluminum surface in $0.05 \mathrm{M} \mathrm{NaCl}$ solution obtained from weight loss method at $28^{\circ} \mathrm{C}$.

Therefore, $\mathrm{Al}^{3+}$ reacts with $\mathrm{OH}^{-}$to form aluminum hydroxide near the aluminum surface as follows:

$$
4 \mathrm{Al}+3 \mathrm{O}_{2}+6 \mathrm{H}_{2} \mathrm{O} \longrightarrow 4 \mathrm{Al}(\mathrm{OH})_{3}
$$

3.3. Scanning Electron Microscopy (SEM). The surface morphology of the aluminum alloy surface in saline environment in the absence and presence of ferrous gluconate after 28 days of immersion in sodium chloride medium is shown in Figure 5. The surface seen in Figure 5(a) is due to the chloride ions attack on the aluminum alloy sample. Flakes showing corrosion products like metal hydroxides and its oxides can be observed [13]. The corrosion process in deep seawater occurs under very specific conditions and is characterized mainly by high chloride contents and the presence of $\mathrm{CO}_{2}$, microorganisms, and $\mathrm{H}_{2} \mathrm{~S}$ [36]. Figure 5(b) shows the SEM micrograph of the specimen after 28 days of immersion in sodium chloride with the presence of ferrous gluconate. It was observed that the corrosion products on the surface of the aluminum in sodium chloride with ferrous gluconate condition are minimal when compared with the micrograph in the absence of inhibitor (Figure 5(a)). The surface of the specimen was noticed to be enclosed with a thin layer of the

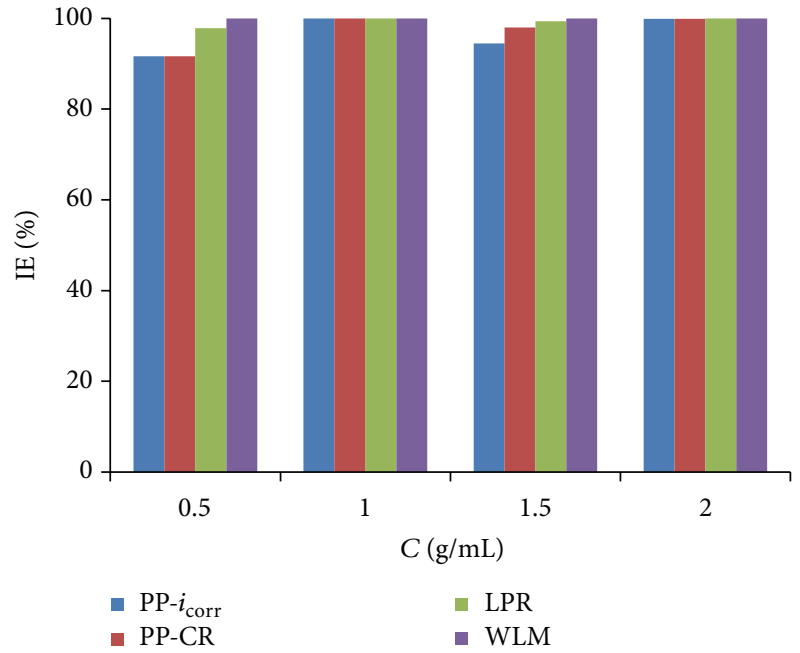

FIgURE 7: Comparative chart of inhibitor efficiency (IE) of aluminum alloy in $0.05 \mathrm{M} \mathrm{NaCl}$ solution in the presence of different concentrations of ferrous gluconate obtained from weight loss and potentiodynamic polarization methods.

ferrous gluconate molecules which protects the metal against corrosion [35].

3.4. Adsorption Behavior. Figure 6 shows the Langmuir adsorption isotherms of ferrous gluconate on the aluminum alloy corrosion in $0.05 \mathrm{M} \mathrm{NaCl}$ solution. The linearity in the result at various concentrations of ferrous gluconate proves that the inhibition effect of the inhibitor was as a result of the adsorption of ferrous gluconate on the surface of the metal. The degree of surface coverage $(\theta)$ obtained from weight loss test varied linearly with the inhibitor concentration which fit for Langmuir adsorption isotherm [37]. Since the correction factors $\left(R^{2}\right)$ is unity (1), the adsorption behaviour of the inhibitor is assumed to have obeyed Langmuir adsorption isotherms.

3.5. Inhibitor Efficiency. The percentage inhibition efficiency (\%IE) of aluminum alloy in saline environment in the 


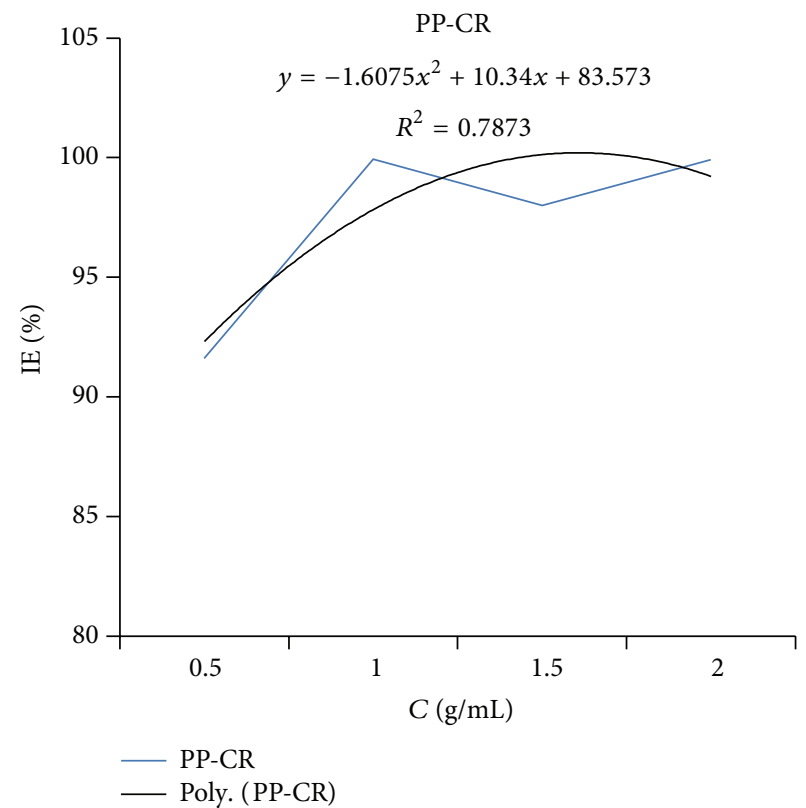

(a)

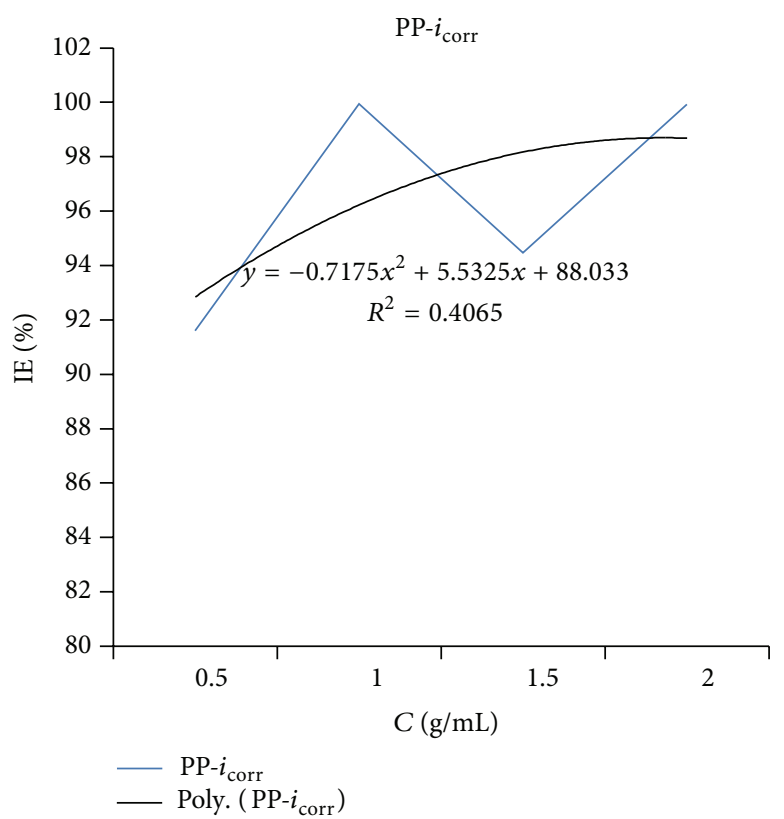

(b)

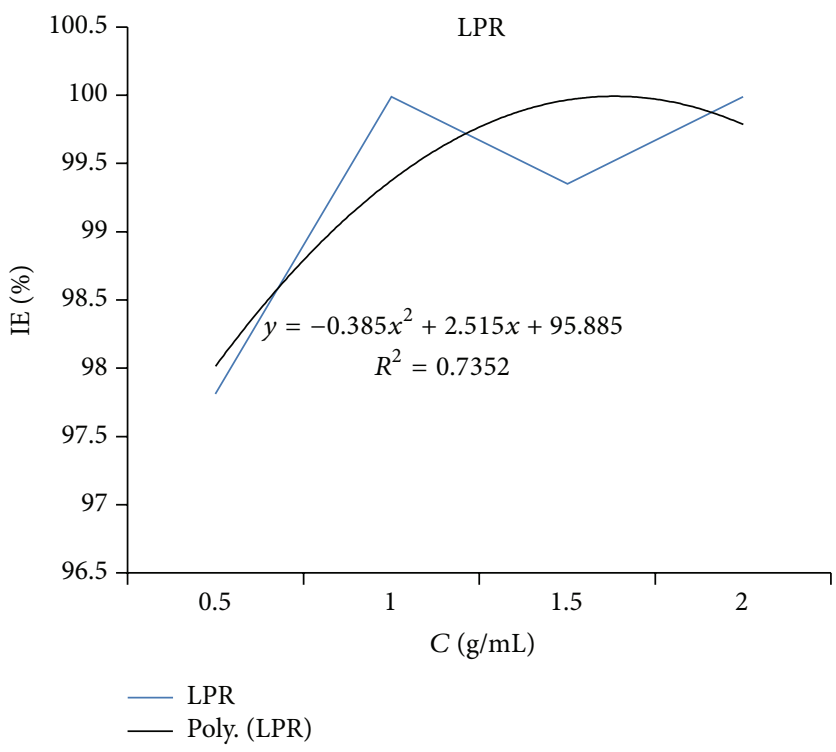

(c)

FIGURE 8: Relationship between concentration and corrosion rate (CR), current density $\left(i_{\text {corr }}\right)$ and linear polarization (LPR).

presence of different concentrations of ferrous gluconate was obtained using equation reported elsewhere $[15,17]$ from weight loss and potentiodynamic polarization techniques. The values of IE (\%) from the weight loss, linear polarization resistance (LPR), potentiodynamic polarizationcorrosion rate (PP-CR), and potentiodynamic polarizationcurrent density $\left(\mathrm{PP}-i_{\text {corr }}\right)$ measurements obtained by using following equations:

$$
\begin{aligned}
& \operatorname{IEPP-i} i_{\text {corr }}(\%)=100 \times \frac{i_{\text {corr }}-i_{\text {corr }}^{\circ}}{i_{\text {corr }}}, \\
& \operatorname{IE~PP-CR~}(\%)=100 \times \frac{\mathrm{CR}-\mathrm{CR}^{\circ}}{\mathrm{CR}},
\end{aligned}
$$

$$
\begin{aligned}
& \operatorname{IE} \operatorname{PP}-\operatorname{LPR}(\%)=100 \times \frac{\mathrm{Rp}^{\circ}-\mathrm{Rp}}{\mathrm{Rp}}, \\
& \operatorname{IE} \operatorname{WLM}(\%)=100 \times \frac{\mathrm{CR}-\mathrm{CR}^{\circ}}{\mathrm{CR}} .
\end{aligned}
$$

The calculated data for the percentage inhibition efficiency using weight loss method (WLM), potentiodynamic polarization-corrosion rate (PP-CR), linear polarization resistance (LPR), and potentiodynamic polarizationcorrosion current density (PP- $i_{\text {corr }}$ ) are presented in Figure 7. All these parameters showed a similar trend. From the result, it is evident that the IE (\%) obtained by different methods 
are in good agreement at all the concentrations of inhibitor studied. Similar result was documented in [35].

$P P-i_{\text {corr }}$. The graphical trend shows that the variation of the concentration does bring about a change in $\mathrm{PP}-i_{\text {corr }}$ value; however, it is not dependent on the concentration; linear relationship was not observed.

$P P-C R$. The graphical trend/regression analysis shows good polynomial relationship between the concentration and corrosion rate. It can be inferred that the PP-CR is dependent on the concentration.

$L P R$. The regression analysis shows a polynomial relationship; hence one can infer that there is a stochastic relation between LPR and concentration.

WLM. The variation of the concentration does not bring about any change in the weight loss.

In summary, from the results obtained, one can deduce that the best inhibitor performance can be achieved at optimal concentration of $1.0 \mathrm{~g} / \mathrm{mL}$ for all parameters measured (PP- $i_{\text {corr }}$, PP-CR, LPR, and WLM).

\section{Conclusions}

The experimental investigation of the use of ferrous gluconate as corrosion inhibitor in sodium chloride medium led to the following deductions.

(i) Ferrous gluconate acted as an effective corrosion inhibitor for aluminum alloy in sodium chloride environment at $28^{\circ} \mathrm{C}$.

(ii) It was established that the optimum concentration of ferrous gluconate that should be used as corrosion inhibitor is $1.0 \mathrm{~g} / \mathrm{mL}$ at $28^{\circ} \mathrm{C}$.

(iii) Polarization result shows that ferrous gluconate acted as a mixed type corrosion inhibitor; adsorption on the aluminum alloy surface obeys Langmuir's adsorption isotherm.

(iv) The percentage inhibition efficiency obtained from weight loss and potentiodynamic polarization techniques were found to correlate with each other.

\section{Acknowledgments}

This work is supported financially by the National Research Foundation. The authors also acknowledge the support from Tshwane University of Technology, Pretoria, South Africa, which helped to accomplish this work.

\section{References}

[1] M. Abdulwahab, I. A. Madugu, S. A. Yaro, S. B. Hassan, and A. P. I. Popoola, "Effects of multiple-step thermal ageing treatment on the hardness characteristics of A356.0-type Al-Si-Mg alloy," Materials and Design, vol. 32, no. 3, pp. 1159-1166, 2011.

[2] M. Metikoš-Huković, R. Babić, and Z. Grubač, “The study of aluminium corrosion in acidic solution with nontoxic inhibitors," Journal of Applied Electrochemistry, vol. 32, no. 1, pp. 35-41, 2002.

[3] M. A. Amin, H. H. Hassan, O. A. Hazzazi, and M. M. Qhatani, "Role of alloyed silicon and some inorganic inhibitors in the inhibition of meta-stable and stable pitting of $\mathrm{Al}$ in perchlorate solutions," Journal of Applied Electrochemistry, vol. 38, no. 11, pp. 1589-1598, 2008.

[4] A. M. Al-Turkustani and M. M. Al-Solmi, "Corrosion inhibition of aluminium in acidic solution by aqueous extract of ajowan plant as green inhibitor," Journal of Asian Scientific Research, vol. 1, pp. 346-358, 2011.

[5] R. Khandelwal, S. Sahu, S. K. Arora, and S. P. Mathur, "Study of corrosion inhibition efficiency of naturally occurring plant cordial dicotoma on aluminium in acidic media," Journal of Corrosion Science and Engineering, vol. 13, 2010, Preprint 12.

[6] M. Kliškić, J. Radošević, S. Gudić, and V. Katalinić, "Aqueous extract of Rosmarinus officinalis L. as inhibitor of Al-Mg alloy corrosion in chloride solution," Journal of Applied Electrochemistry, vol. 30, no. 7, pp. 823-830, 2000.

[7] C. A. Loto and A. P. I. Popoola, "Plants extracts corrosion inhibition of aluminium alloy in $\mathrm{H}_{2} \mathrm{SO}_{4}$," Canadian Journal of Pure and Applied Sciences, vol. 6, pp. 1973-1980, 2012.

[8] S. S. Abdel Rehim, H. H. Hassan, and M. A. Amin, "Chronoamperometric studies of pitting corrosion of $\mathrm{Al}$ and (Al-Si) alloys by halide ions in neutral sulphate solutions," Corrosion Science, vol. 46, no. 8, pp. 1921-1938, 2004.

[9] E. McCafferty, "Competitive adsorption model for the inhibition of crevice corrosion and pitting," Journal of the Electrochemical Society, vol. 137, no. 12, pp. 3731-3737, 1990.

[10] P. L. Cabot, F. A. Centellas, E. Pérez, and R. Loukili, "Pitting and repassivation processes of $\mathrm{AlZnMg}$ alloys in chloride solutions containing sulphate," Electrochimica Acta, vol. 38, no. 18, pp. 2741-2748, 1993.

[11] G. Blustein, J. Rodriguez, R. Romanogli, and C. F. Zinola, "Inhibition of steel corrosion by calcium benzoate adsorption in nitrate solutions," Corrosion Science, vol. 47, no. 2, pp. 369383, 2005.

[12] K. C. Emregül, A. Abdülkadir Akay, and O. Atakol, "The corrosion inhibition of steel with Schiff base compounds in 2 M HCl," Materials Chemistry and Physics, vol. 93, no. 2-3, pp. 325-329, 2005.

[13] B. Gao, X. Zhang, and Y. Sheng, "Studies on preparing and corrosion inhibition behaviour of quaternized polyethyleneimine for low carbon steel in sulfuric acid," Materials Chemistry and Physics, vol. 108, no. 2-3, pp. 375-381, 2008.

[14] P. B. Raja and M. G. Sethuraman, "Natural products as corrosion inhibitor for metals in corrosive media-a review," Materials Letters, vol. 62, no. 1, pp. 113-116, 2008.

[15] A. Singh and M. A. Quraishi, "Azwain (Trachy-Spermum copticum) seed extract as an efficient corrosion inhibitor for aluminium in $\mathrm{NaOH}$ solution," Research Journal of Recent Sciences, vol. 1, pp. 57-61, 2012.

[16] R. A. Mohammed, M. Abdulwahab, I. A. Madugu, J. O. Gaminana, and F. Asuke, "Inhibitive effect by natural Cyperus esculentus L. oil on the corrosion of A356. 0-type Al-Si-Mg alloy in simulated seawater environment," Journal of Material Environmental Science, vol. 1, pp. 93-98, 2013.

[17] P. D. R. Kumari, J. Nayak, and A. N. Shetty, "3-Methyl-4-amino5-mercapto-1,2,4-triazole as corrosion inhibitor for 6061/Al15 (Vol-\%) Sic (p) composite on $0.5 \mathrm{M}$ sodium hydroxide solution," Journal of Material Environmental Science, vol. 4, pp. 387402, 2011. 
[18] R. Li, X. Y. Li, J. Pang et al., "Passivation behaviour of Al88Fe6La6 glassy alloy in $\mathrm{NaOH}$ and $\mathrm{H}_{2} \mathrm{SO}_{4}$ solutions," International Journal of Electrochemical Science, vol. 8, pp. 29832995, 2013.

[19] I. C. Madufor, U. E. Itodoh, M. U. Obidiegwu, and M. S. Nwakaudu, "Inhibition of aluminium corrosion in acidic medium by chrysophyllum albidum (African star apple) fruit extract," Journal of Engineering, vol. 2, pp. 16-23, 2012.

[20] O. K. Abiola, N. C. Oforka, A. O. Ifelebuegu, T. M. Fasina, and A. I. Babatunde, "Effect of diphenyl thiocarbazone and diphenylcarbazone on acid corrosion of aluminium in $\mathrm{HCl}$ solution. Part 1," Journal of Scientific Research and Development, vol. 11, pp. 1-8, 2009.

[21] P. D. Reena Kumari, J. Nayak, and A. Nityananda Shetty, "3ethyl-4-amino-5-mercapto-1,2,4-triazole as corrosion inhibitor for 6061-alloy in sodium hydroxide solution," Portugaliae Electrochimica Acta, vol. 29, no. 6, pp. 445-462, 2011.

[22] I. O. Arukalam and M. U. Obidiegwu, "The inhibition of aluminium corrosion in hydrochloric acid solution by hydroxyethyl cellulose," Academic Research International, vol. 1, pp. 484-491, 2011.

[23] A. P. I. Popoola, O. S. I. Fayomi, and M. Abdulwahab, "Degradation behaviour of aluminium in $2 \mathrm{M} \mathrm{HCl} / \mathrm{HNO} 3$ in the presence of arachis hypogeae natural oil," International Journal of Electrochemical Science, vol. 7, pp. 5817-5827, 2012.

[24] I. B. Obot and N. O. Obi-Egbedi, "Fluconazole as an inhibitor for aluminium corrosion in 0.1 M HCl," Colloids and Surfaces A, vol. 330, no. 2-3, pp. 207-212, 2008.

[25] S. J. García, T. H. Muster, Ö. Özkanat et al., “The influence of pH on corrosion inhibitor selection for 2024-T3 aluminium alloy assessed by high-throughput multielectrode and potentiodynamic testing," Electrochimica Acta, vol. 55, no. 7, pp. 2457-2465, 2010.

[26] S. A. Umoren and M. M. Solomon, "Effect of halide ions additives on the corrosion inhibition of aluminum in $\mathrm{HCl}$ by polyacrylamide," The Arabian Journal for Science and Engineering, vol. 35, pp. 115-129, 2010.

[27] M. A. Amin, S. S. Abd El Rehim, and A. S. El-Lithy, "Pitting and pitting control of $\mathrm{Al}$ in gluconic acid solutions-polarization, chronoamperometry and morphological studies," Corrosion Science, vol. 52, no. 9, pp. 3099-3108, 2010.

[28] O. Sanni, C. A. Loto, and A. P. I. Popoola, "Electrochemical assessment of zinc gluconate as inhibitor on mild steel in a saline environment," Research on Chemical Intermediates, 2013.

[29] R. Touir, M. Cenoui, M. El Bakri, and M. Ebn Touhami, "Sodium gluconate as corrosion and scale inhibitor of ordinary steel in simulated cooling water," Corrosion Science, vol. 50, no. 6, pp. 1530-1537, 2008.

[30] F. Ivusic, O. Lahodny-Sarc, and V. Alar, "Corrosion inhibition of carbon steel in various water types by zinc gluconate," Material, vol. 44, pp. 319-329, 2013.

[31] O. Lahodny-Šarc and S. Popov, "Corrosion inhibition of mild steel in sodium gluconate-borate solutions," Surface and Coatings Technology, vol. 34, no. 4, pp. 537-547, 1988.

[32] S. A. M. Refaey, "Passivation and pitting corrosion of tin in gluconate solutions and the effect of halide ions," Journal of Applied Electrochemistry, vol. 26, no. 5, pp. 503-507.

[33] A. Singh, A. K. Singh, and M. A. Quraishi, "Dapsone: a novel corrosion inhibitor for mild steel in acid media," The Open Electrochemistry Journal, vol. 2, pp. 43-51, 2010.
[34] E. W. Abel, "The literature of inorganic chemistry," in Comprehensive Inorganic Chemistry II, J. C. Bailar, Ed., Pergamon, Oxford, UK, 1965.

[35] R. Rosliza, "Improvement of corrosion resistance of aluminium alloy by natural products," in Corrosion Resistance, H. Shih, Ed., pp. 377-395, InTech, 2012.

[36] A. Yağan, N. Ö. Pekmez, and A. Yildiz, "Corrosion inhibition by poly(N-ethylaniline) coatings of mild steel in aqueous acidic solutions," Progress in Organic Coatings, vol. 57, no. 4, pp. 314318, 2006.

[37] I. Langmuir, "The constitution and fundamental properties of solids and liquids. Part I. Solids," The Journal of the American Chemical Society, vol. 38, no. 2, pp. 2221-2295, 1916. 

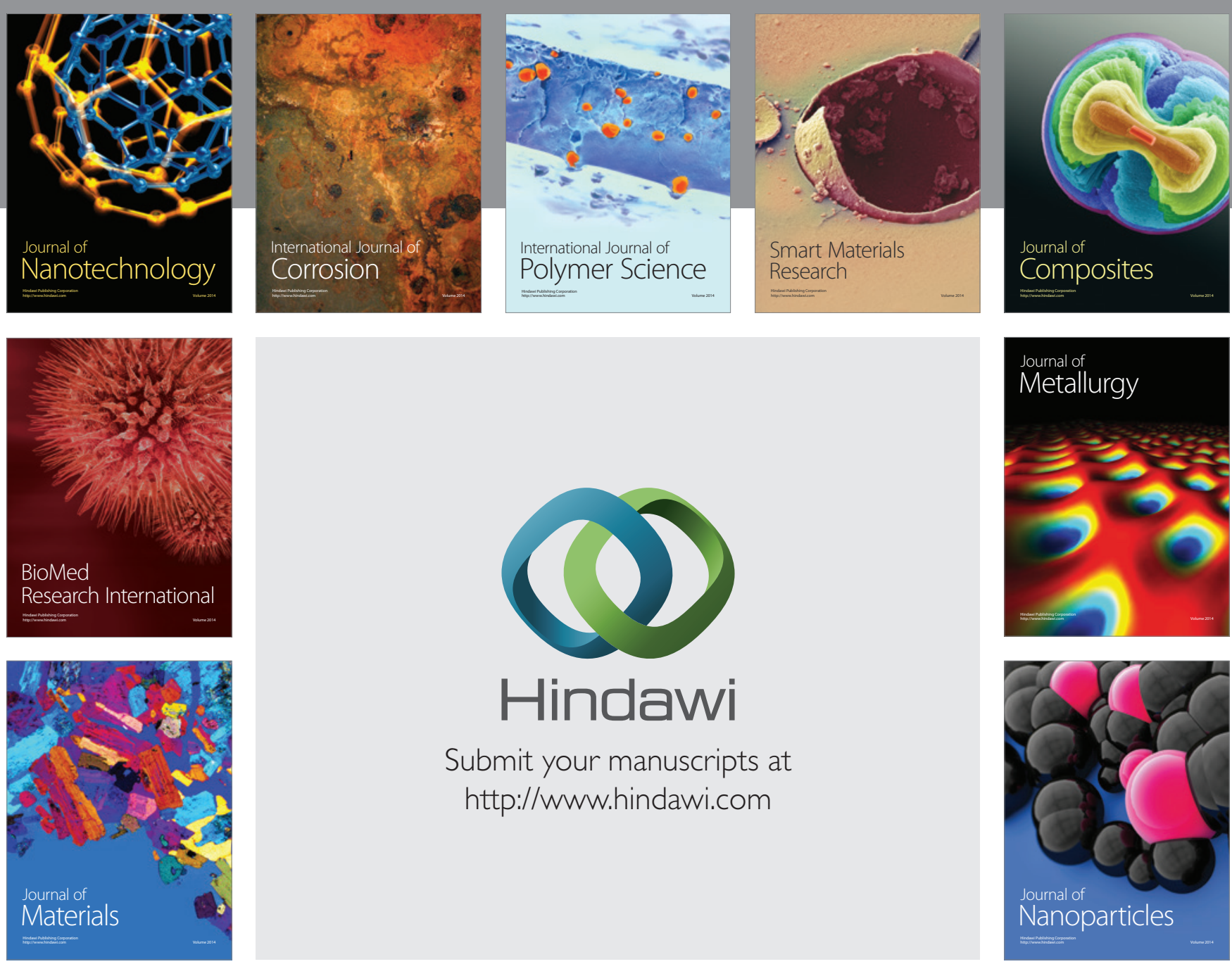

Submit your manuscripts at http://www.hindawi.com
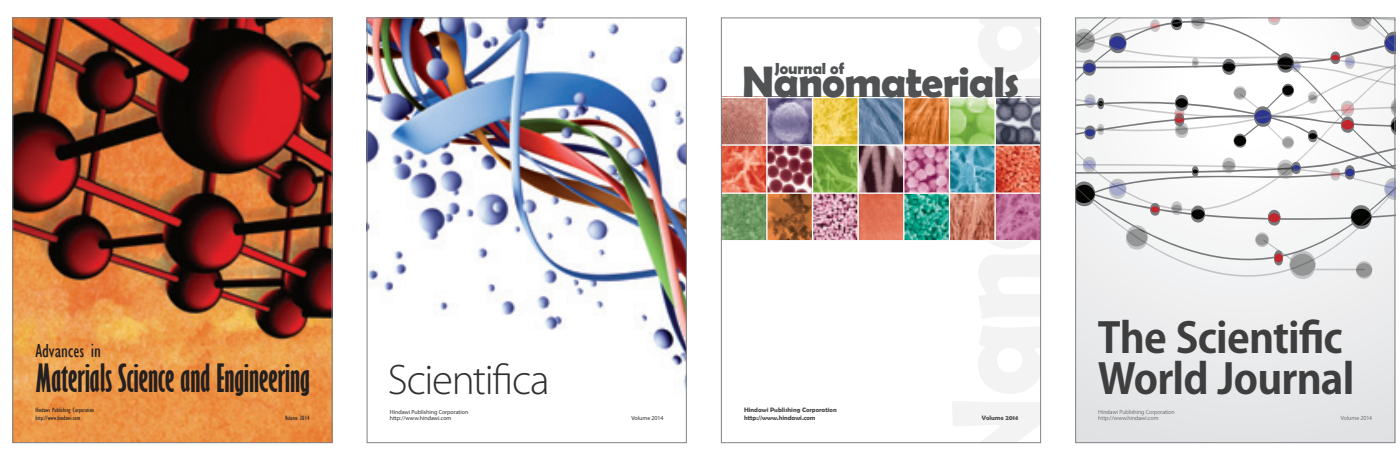

\section{The Scientific World Journal}
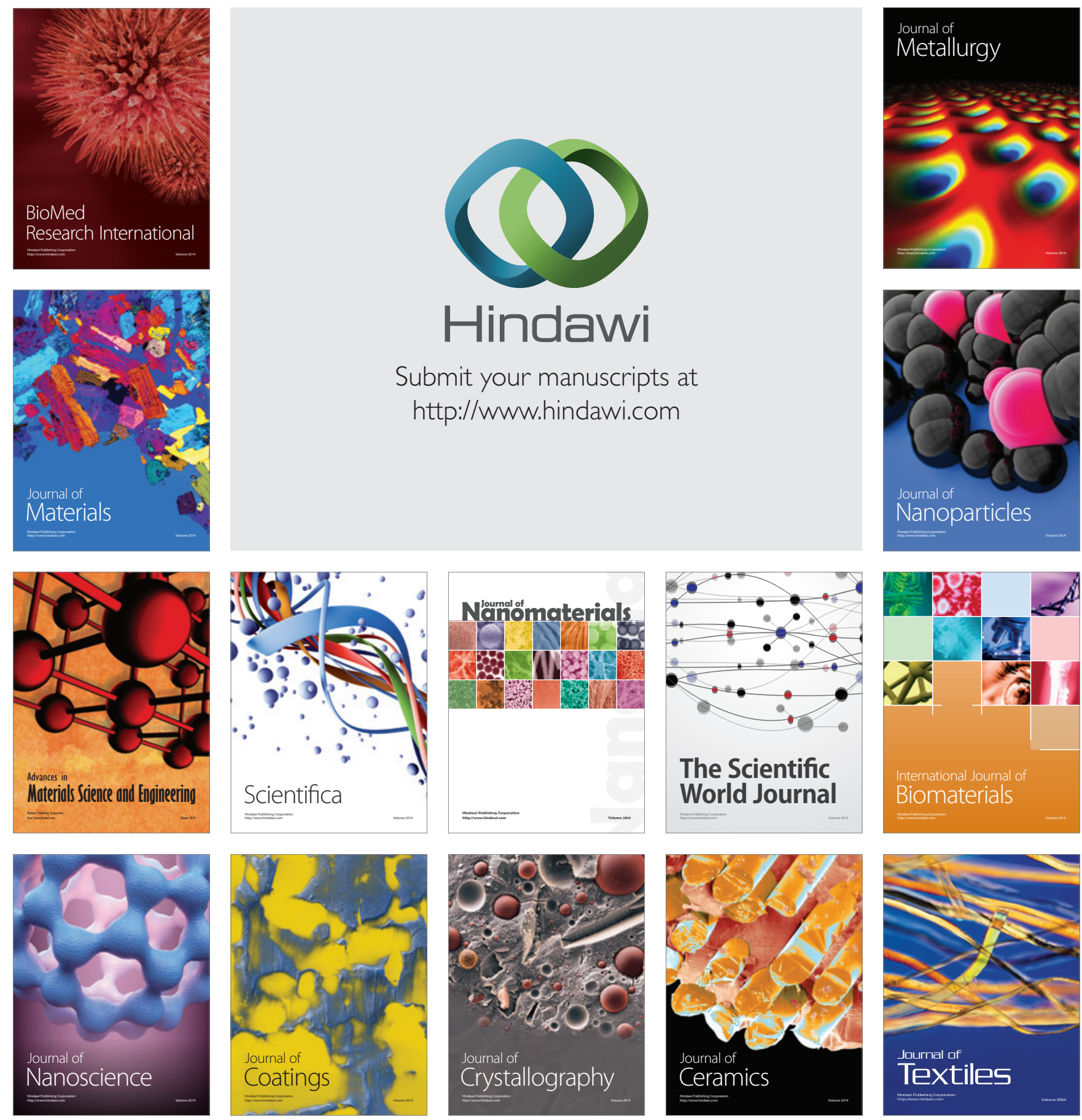